Supplement of Biogeosciences, 18, 1559-1575, 2021 https://doi.org/10.5194/bg-18-1559-2021-supplement (C) Author(s) 2021. This work is distributed under the Creative Commons Attribution 4.0 License.

(c) (1)

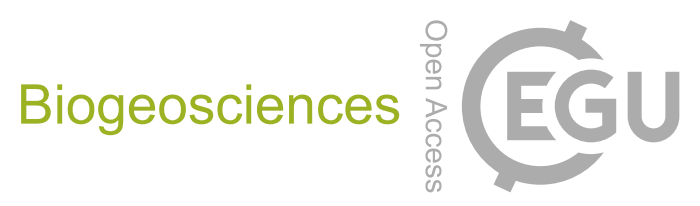

Supplement of

\title{
Comparison of greenhouse gas fluxes from tropical forests and oil palm plantations on mineral soil
}

Julia Drewer et al.

Correspondence to: Julia Drewer (juew@ceh.ac.uk)

The copyright of individual parts of the supplement might differ from the CC BY 4.0 License. 


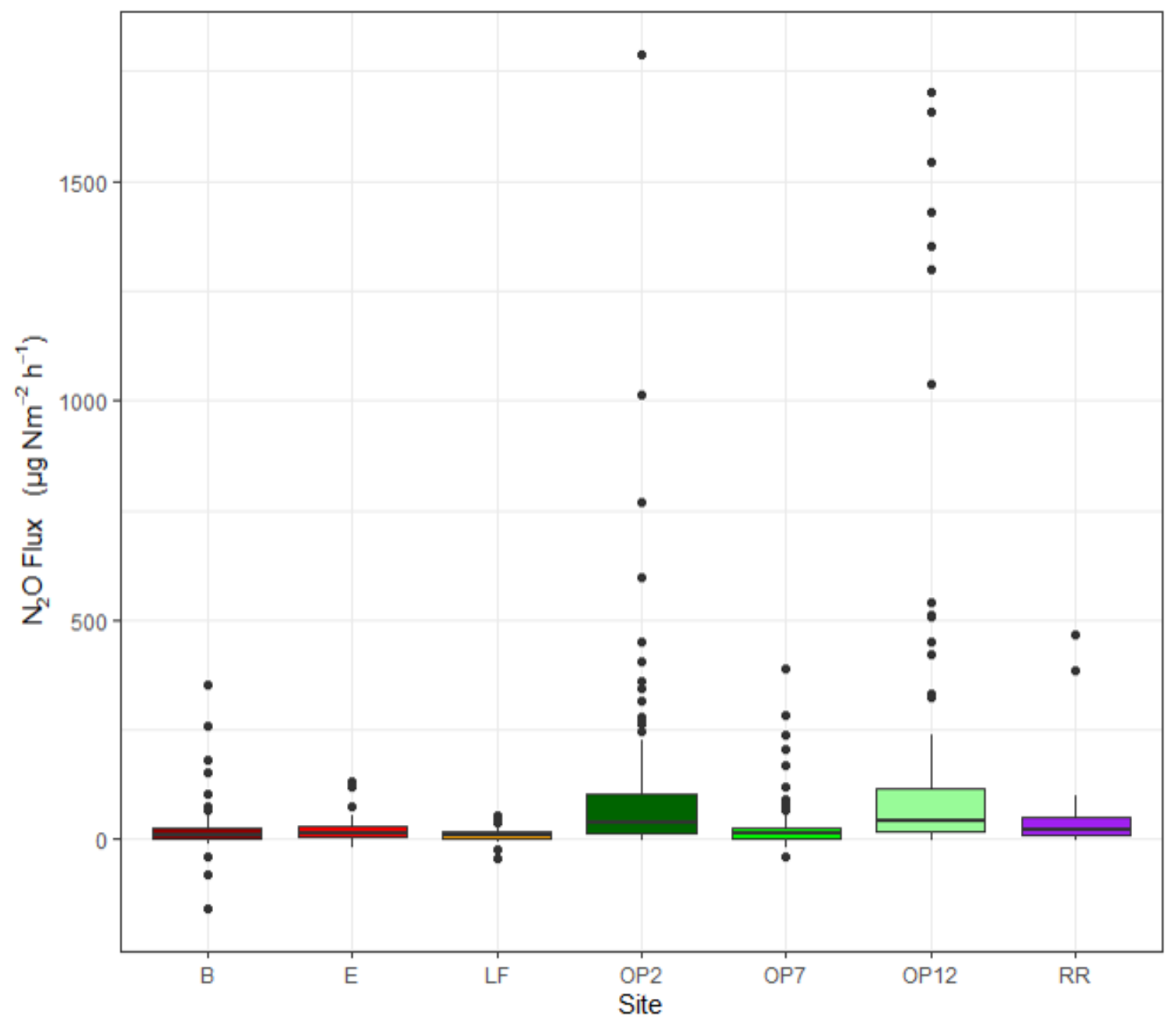

15

16 Figure S1. Nitrous oxide $\left(\mathrm{N}_{2} \mathrm{O}-\mathrm{N}\right)$ fluxes in $\mu \mathrm{g} \mathrm{m}^{-2} \mathrm{~h}^{-1}$ from January 2015 - November 2016, every two

17 months (B, E, LF $=$ logged forests, OP2, OP7, OP12 = oil palm plantations, $\mathrm{RR}=$ riparian reserve). The

18 ends of the box are the upper and lower quartiles, so the box spans the interquartile range. The median is

19 marked by a horizontal line inside the box. The whiskers are the two lines outside the box that extend to

20 the highest and lowest observations with outliers marked with an asterisk $(*)$. 


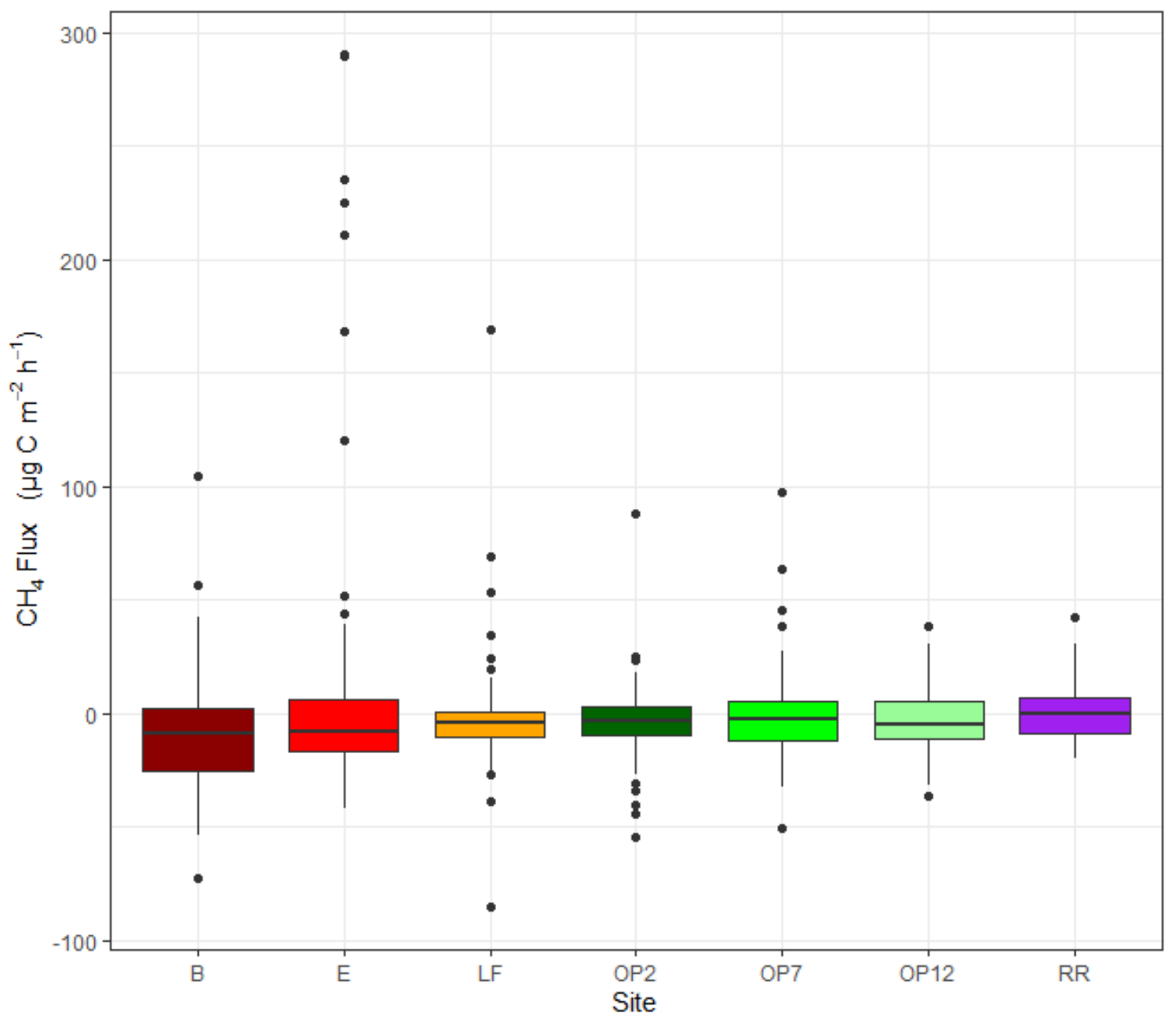

23 Figure S2. Methane $\left(\mathrm{CH}_{4}-\mathrm{C}\right)$ fluxes in $\mu \mathrm{g} \mathrm{m}^{-2} \mathrm{~h}^{-1}$ from January 2015 - November 2016, every two months

$24(\mathrm{~B}, \mathrm{E}, \mathrm{LF}=$ logged forests, OP2, OP7, OP12 = oil palm plantations, $\mathrm{RR}=$ riparian reserve). The ends of

25 the box are the upper and lower quartiles, so the box spans the interquartile range. The median is marked

26 by a horizontal line inside the box. The whiskers are the two lines outside the box that extend to the

27 highest and lowest observations with outliers marked with an asterisk (*). 


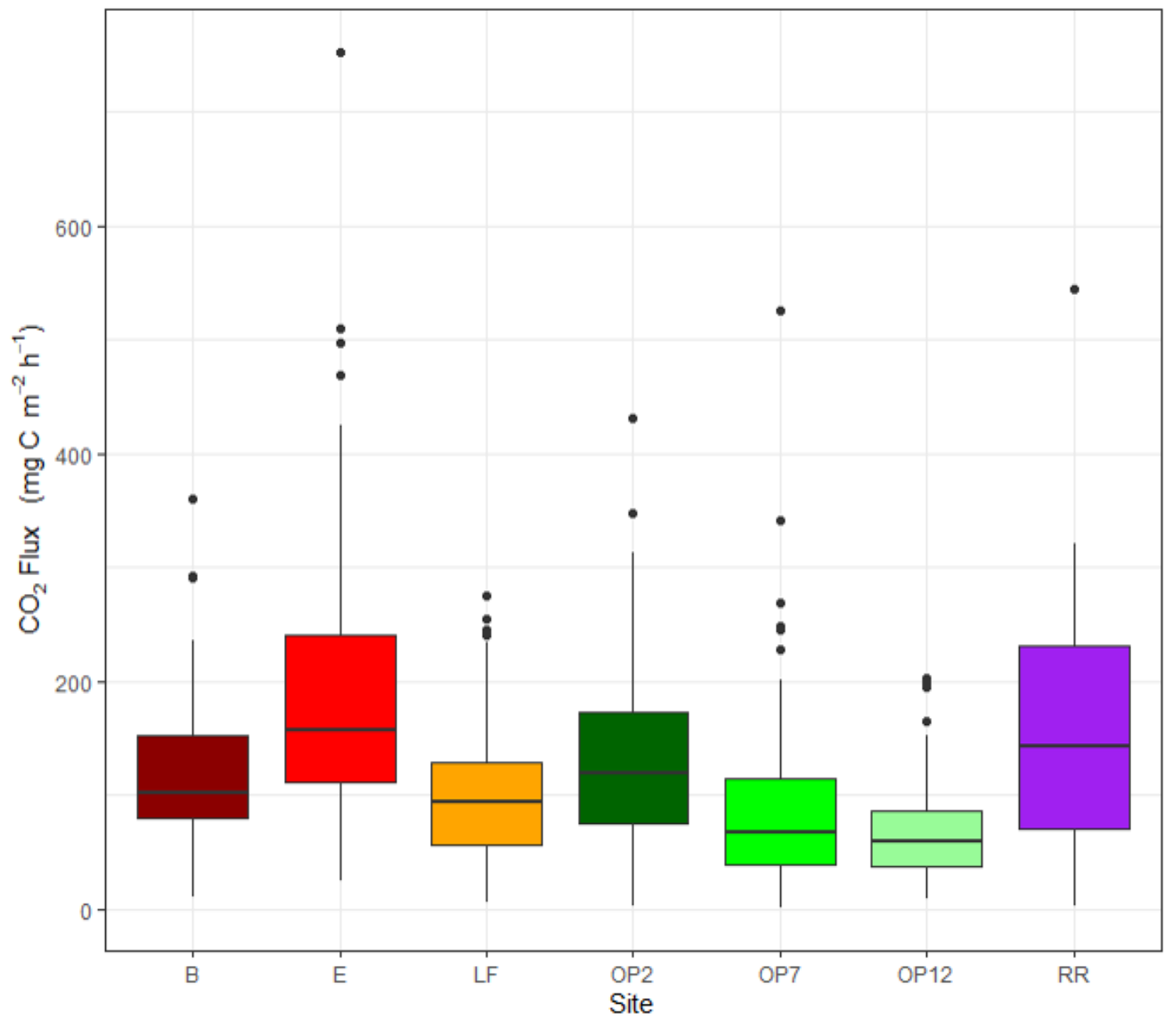

30 Figure S3. Soil respiration $\left(\mathrm{CO}_{2}-\mathrm{C}\right)$ rates in $\mathrm{mg} \mathrm{m}^{-2} \mathrm{~h}^{-1}$ from January 2015 - November 2016, every two

31 months ( $\mathrm{B}, \mathrm{E}, \mathrm{LF}=$ logged forests, $\mathrm{OP} 2, \mathrm{OP} 7, \mathrm{OP} 12=$ oil palm plantations, $\mathrm{RR}=$ riparian reserve). The

32 ends of the box are the upper and lower quartiles, so the box spans the interquartile range. The median is

33 marked by a horizontal line inside the box. The whiskers are the two lines outside the box that extend to

34 the highest and lowest observations with outliers marked with an asterisk $(*)$. 
36 Table S1. Relationships between environmental variables and microbial community structure,

37 determined by linear fitting of vectors to the NMDS ordination axis scores at sample t2 (see Fig 7).

38 Significance of fits is displayed as $* * * \mathrm{p}<=0.001, * * \mathrm{p}<=0.01$, and $* \mathrm{p}<=0.05$.

39

40

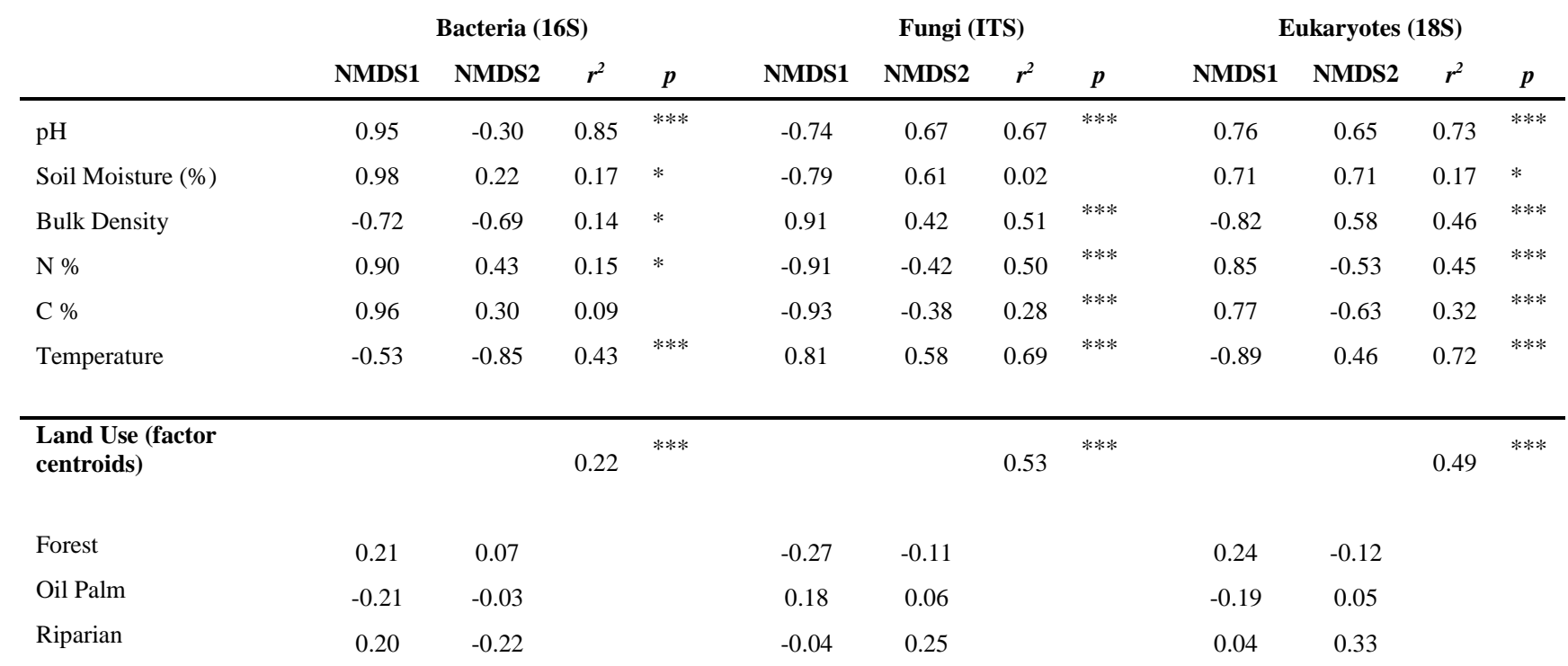

